\title{
HYPERLOOP: FIFTH MODE OF TRANSPOTATION
}

\author{
Mr. Kaushal S. Pathare \\ Mechanical Engineering \\ Savitribai Phule Pune University INDIA,
}

\begin{abstract}
Existing conventional modes of transportation of people consists of four unique types: rail, road, water, and air. These modes of transport tend to be either relatively slow (i.e., road and water), expensive (i.e., air), or a combination of relatively slow and expensive (i.e., rail). Hyperloop is a new mode of transport that seeks to change this paradigm by being both fast and inexpensive for people and goods. Hyperloop is also unique in that it is an open design concept, similar to Linux. Feedback is desired from the community that can help advance the Hyperloop design and bring it from concept to reality.
\end{abstract}

Keywords - transportation, inexpensive, magnetic accelerators, safely environment, Elon Musk

\section{INTRODUCTION}

Hyperloop is a completely new mode of fastest transportation. Hyperloop is firstly proposed by Elon musk and a team of engineer from Tesla Motors and the Space Exploration Technologies Corporation in August 2013. The concept of hyperloop includes travelling people from one place to another place in a capsule which is propelling at a very high speed. We can also called hyperloop as a solar powered transportation system and it is an alternative of high speed train. Basically hyperloop is magnetically levitated train which runs inside a long tube or pipe. It consists of low pressure tube with capsule that is transported at both low and high speeds. It is driven by linear induction motor and compressor. It includes 28 passenger pods. For propulsion, magnetic accelerators will be planted along the length of the tube, propelling the pods forward. The tubes would house a low pressure environment, surrounding the pod with a cushion of air that permits the pod to move safely at such high speeds, like a puck gliding over an air hockey table. Given the tight quarters in the tube, pressure buildup in front of the pod could be a problem. The tube needs a system to keep air from building up in this way. Musk's design recommends an air compressor on the front of the pod that will move air from the front to the tail, keeping it aloft and preventing pressure building up due to air displacement. A one way trip on the Hyperloop is projected to take about 35 minutes (for comparison, traveling the same distance by car takes roughly six hours.) Passengers may enter and exit Hyperloop at stations located either at the ends of the tube,

\section{HISTORICAL DEVELOPMENT OF BIOMETRIC TECHNOLOGY}

Concepts for high-speed trains in vacuum or evacuated tubes can be traced back as far as 1909, when rocket pioneer Robert $\mathrm{H}$. Goddard proposed high-speed passenger-carrying pods traveling through evacuated tubes. Bachelet introduced the core idea behind magnetically levitating trains as early as 1910 Over the years these ideas have been further rened, for instance by the Rand Corporation in 1972 with their "Very High Speed Transport System" The Hyperloop Alpha white paper combined several of these historic concepts and spurred a great deal of public interest in the concept, something the earlier ideas were somewhat lacking. This white paper discusses a Hyperloop pod that travels at $1220 \mathrm{~km} / \mathrm{h}$ in partially evacuated tube (1/1000th of atmospheric pressure) levitating using air bearings.

\section{The First Hyperloop}

Over a press conference in August 2013, the South Africanborn and world-wide active entrepreneur Elon Musk (founder of PayPal, SpaceX, Tesla, ...) proposed, under the designation "Hyperloop" a novel transportation system, and described it in detail in a concept paper. It is remarkable that Musk does not ask for any license fees on the proposed concept ("open source" concept) - therefore, since 2013 a number of private enterprises have been established for the development and marketing of Hyperloop-based systems

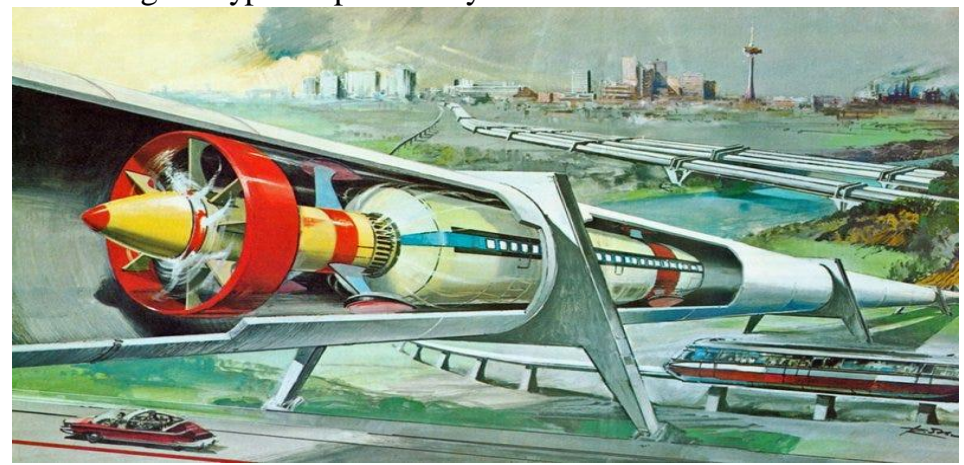

Fig1-Historical development of hyperloop

\section{LITERATUREE SURVEY}

Ahmed Hodaib, Samar F. Abdel Fattah (May 2016), discussed the design of a hyperloop capsule with linear induction 
propulsion system which is used to accelerate and decelerate the capsule. They studied that like rotary synchronous motors; linear motors run on 3-phase power and can support very high speeds. However, there are end effects that reduce the motor's thrust force. Linear induction motors are thus less energy efficient than normal rotary motors for any required force output. They also discussed about the manufacturing of linear induction motor in this paper.[1]

Mark Sakowski (2016) discussed the current maglev technology along with the theoretical evacuated tube technology and they concluded that the hyperloop is feasible and if properly designed, has the potential to be much more efficient in terms of energy usage of pods traversing down the tube.[2]

N. Kayela, (2014) investigated that the hyperloop is a fifth mode of transportation alongside trains, planes, automobiles and boats. He discussed about the railway track for the hyperloop, stations for the hyperloop. Also, discussed about the two version of capsule that is one is passenger only version and another is passenger plus vehicle version.[3]

Mohammed Imran (2016) He focused his study element on the hyperloop technology (the passenger transport system). He discussed about the two version of hyperloop in that one is passenger only version and another is passenger plus vehicle version. Hyperloop System.[4]

\section{SYSTEM DESIGN}

Hyperloop is based on a principle of magnetic levitation. The principle of magnetic levitation is that a vehicle can be suspended and propelled on a guidance track made with magnets. The vehicle on top of the track may be propelled with the help of a linear induction motor.

\section{Components of hyperloop}

\section{Tube}

The tube is made of steel and it is double layered to ensure safety. Two tubes are welded together side by side configuration to allow the travel in both directions and are supported by pillars. Solar arrays are provided on the top of the tubes to make this, a self powering system

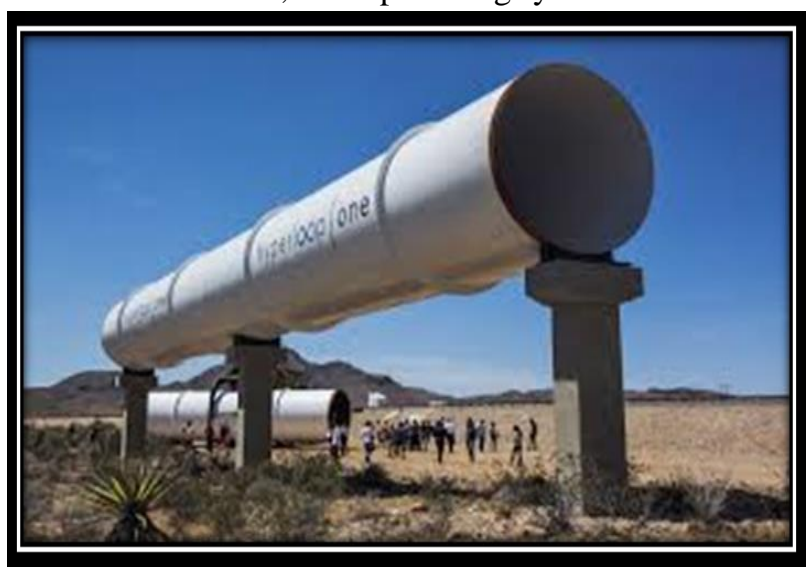

Fig2- Hyperloop tube

\section{POD}

The pods are similar to train bogie and first generation pod of as shown in fig-3is made with sandwich system, where you have outer and inner skin that makes you sure that your always safe. Each pod can carry 28 passengers per travel. Permanent magnets are arranged at bottom of pod for levitation and augmented windows are arranged in Xp-1 pod for refreshment of passengers.

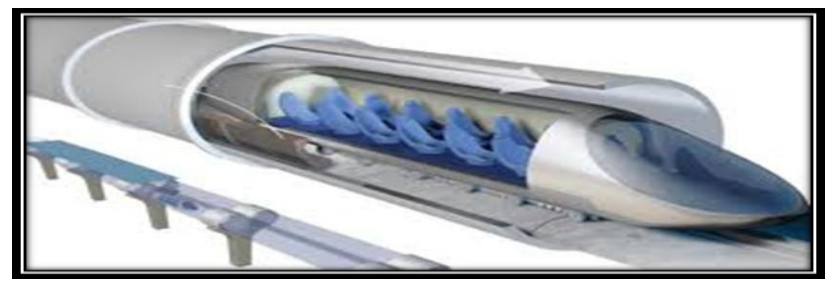

Fig3- Hyperloop pod

\section{PYLON}

The tube will be supported by pylons which constrain the tube in the vertical direction but allow longitudinal slip for thermal expansion as well as dampened lateral slip to reduce the risk posed by earthquakes. These minimally constrained pylons tube joints will also allow a smoother ride, the average spacing is $100 \mathrm{ft}(30 \mathrm{~m})$ and the pillars will be $20 \mathrm{ft}(6 \mathrm{~m})$ tall whenever possible but may vary in height in hilly areas or where obstacles are in the way, pylons are not required in all the places

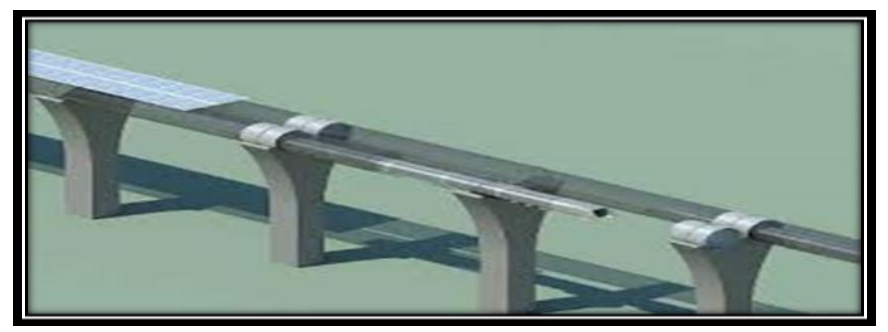

Fig4- Hyperloop pylon

\section{PROPULSION}

The need of the propulsion system are as follows In urban areas the speed should be low so it is maintained between 0 to $480 \mathrm{kmph}$. For mountain or hilly areas the speed is maintained near $480 \mathrm{kmph}$. For the long coasting area the speed is accelerated from 480 to $1220 \mathrm{kmph}$. After the completion of coastal area the speed is decelerated again to $480 \mathrm{kmph}$. 


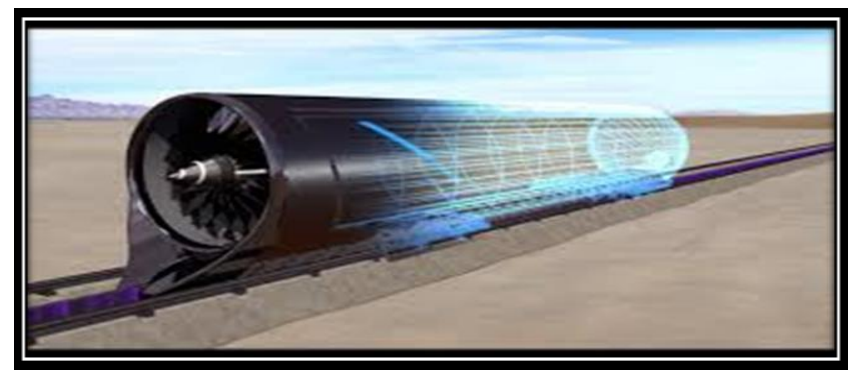

Fig5- Hyperloop propulsion

\section{TECHNOLOGY OVERVIEW}

Trains was presented by the popular American designer, creator, and specialist tycoon Elon Musk. In his work, he portrayed alleged "an alpha adaptation" of the Hyperloop transportation framework improvement in California (USA) interfacing two huge American urban communities Los Angeles and San Francisco. The length of the line is $561 \mathrm{~km}$ in separation.

This twin-tube street is proposed for transportation of travellers. It utilizes two cylinders. In one cylinder driving of the cases guarantees forward, through another cylinder in the invert heading. The cylinder width is $2.23 \mathrm{~m}$. The traveller case has measurements: $1.35 \mathrm{~m}$ in width, $1.1 \mathrm{~m}$ in tallness and 25 to $30 \mathrm{~m}$ long. The travellers in the case be situated in individual seats as in a vehicle. The container has a compartment for the hand rigging of travellers. The tablet suits two columns of seats with 14 situates in individual line, i.e., 28 travellers. The street will probably give the traveller traffic in the total of 840 individuals/hour, which permits accomplishing estimations of the measure of the drive at 7.4 million individuals/year. The development of the train is done utilizing direct electric engines. The moving engine component (rotor) is situated on the case while the cylinder joins the stationary engine stator which controls the vehicle. The motor uses an aluminium sheet as a rotor. The stator windings produce a directly moving attractive field performing on conductors in the field. The aluminium sheet, which is situated around there has swirl flows instigated in it, in this way producing a restricting attractive field. The two inverse fields repulse one another, produce movement of the case. It is conceivable to comprehend increasing speed of the case and its log jam. In the event of speeding up, it can achieve a high subsonic speed and give an intermittent reboot around each $110 \mathrm{~km}$. The base separation (in time) among moving contiguous cases ought to be no less than 30 seconds.

The last strategy, which we are examining here, is related with a detectable increment in weight in the Hyperloop tube. The system utilizes a passage adaptation of vacuum lines with an inside weight of 100 milli bars (indicated as mbar). Note that 100 mbar $=0.1$ bar 104 Dad. Subsequently, the weight in this framework is multiple times more noteworthy than in the Hyperloop framework (100 Dad). Accordingly, the air opposition in the development of the traveller capsule and vitality utilization expanded in this framework. Be that as it may, in the meantime, the plan speed remained rather high $500 \mathrm{~km} / \mathrm{h}$.

\section{HYPERLOOP WORKING}

Working of hyperloop system is based on magnetic levitation principle. As we know that the passenger pad travel through low pressure tube which is pylon-supported tube. In hyperloop system an air compressor fan is fitted on front side of pod which sucks the air. It transfer high pressure air front side to the rear side of capsule (pod) and it propel the pod. It creates the air cushion around the pod, so that the pod is suspended in air within the tube. On the basis of magnetic levitation principle the pod will be propelled by the linear induction motor. By the linear induction motor the capsule send from one place to another place to a subsonic velocity that is slower than the speed of sound. The pod will be self-powered. There is solar panel fitted on top of the tube. By this solar panel there is enough energy is stored in battery packs to operate at night and in cloudy weather for some periods. The energy is also is stored in the form of compressed air. The air between the capsule acts as a cushions to prevent two capsules from colliding within the tube.

In above figure it shown that the air through the compressor is send to a bypass nozzle at the rear end of the capsule. If capsule cover too much area of the tube then, the air is not flow around the capsule and ultimately the entire column of air in the tube is being pushed ahead of the capsule and because of this there is friction between the air and tube walls is increases tremendously. Therefore to avoid this problem the compressor is fitted at the front of the capsule through which the air is flow which will not flow around the capsule and send it to bypass nozzle.

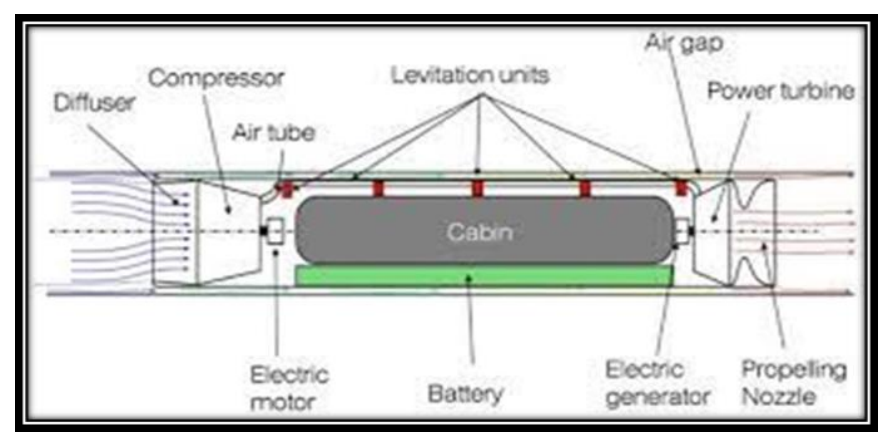

Fig6- Hyperloop system 


\section{International Journal of Engineering Applied Sciences and Technology, 2020 Vol. 4, Issue 11, ISSN No. 2455-2143, Pages 274-278 \\ Published Online March 2020 in IJEAST (http://www.ijeast.com)}

\section{ADVANTAGES}

- The technology offers very fast speed of transportation which is twice that of aircraft.

- It has very low power consumption.

- It is low cost transportation system on long run.

- It is immune to bad weather conditions.

- It is resistant to earthquakes.

\section{DISADVANTAGES}

- High speed of capsule (almost at speed of sound) may cause dizziness to the passengers travelling due to vibration and jostling.

- Initial cost of investment to have the system in place is very high. The long vacuum chamber manufacturing requires more technical skills. Moreover this is costly and also risky to maintain.

- Land use rights will be concern for deployment of the project.

- It has very high risk to life when something wrong happens to the system.

- It has limited space in the train and hence people can not move freely.

- As hyperloop uses steel for track, it expands and changes shape when outside temperature is changed. This may destroy the track of hyperloop technology. This needs to be considered while designing the system based on environment of the location where it is being deployed.

- The installation requires cutting of large number of trees. This leads to environment loss.

\section{FUTURE SCOPE}

If you really want hyperloop, however, you must build a hyperloop. There are lots of renderings and promises out there: The companies in this space have announced plans to build hyperloops in California, Colorado, on the East Coast, in India, Slovenia, Dubai, and Abu Dhabi. Hyperloop One wants a commercial line in service in 2020 .

So what comes next? A bit more engineering, to start. Then real life-and that's when we'll see whether hyperloop can really change the world, or at least get rid of some of the traffic. And if you really want to ride in a hyperloop and you're not a shipping container, you might want to move to Dubai. If any place can sweep away political hurdles and ignore potentially outrageous energy bills, it's the city whose motto might as well be "Sounds shiny and impractical
X. APPLICATIONS

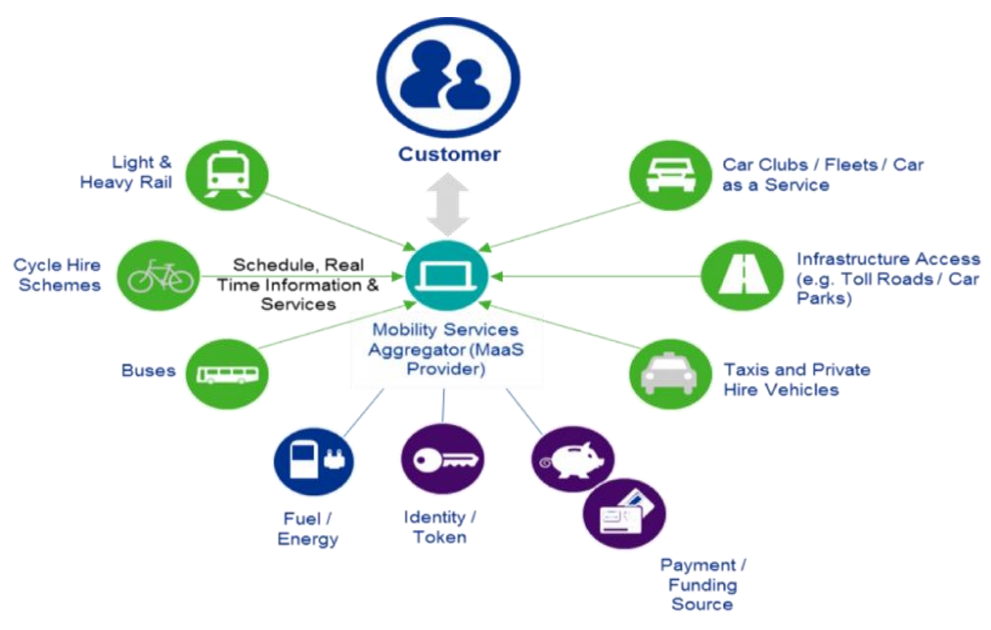

\section{CONCLUSION}

1. A high speed transportation system known as Hyperloop has been developed in this report.

2. Hyperloop transportation system can be used over the conventional modes of transportation that are rail, road, water and air.

3. At very high speed it provides better comfort and cost is also low.

4. By reducing the pressure of the air in the tube which reduces simple air drag and enables the capsule to move faster than through a tube at atmospheric pressure.

\section{REFERANCE}

[1] Hyperloop Alpha (pdf). SpaceX (12 August 2013). The first concept of the system proposed by Musk Elon on August 12, 2013.

[2] http://www.prnewswire.com/newsreleases/hyperloop-oneannounces- semifinalists-ofits-global-Challenge300387186.html

[3] The possible application of Hyperloop technology in the Zarubino Handgun . Materials of the Eastern

[4] https://www.ontlease,ru/catalog/suhogruznye_morski e_kontejnery/

[5] Maglev, https://ru.wikipedia.org/wiki/maglev.

[6] https://www.boringcompany.com

[7] Dudnikov E., Advantages of a new Hyperloop transport technology / Proceedings of the 10th International 
Conference

"Management

of

MaterialsofLarge6FDOH6IVWHP'HYHORSPHQW0/6'E,

2017.

[8] Ashcroft F. On the verge of a possible. - M;Alpina nonfiction. 2018

[9] Hyperloop One: images of the first Hyperloop full-scale test track released. Electrek.co. March 7, 2017

[10] Shinde Rajshri Tukaram 1, Raijade Vaishnavi Balasaheb 2, Lahare Abhishek Sunil 3, Vijay B-IRJET PUBLICATIONS

[11] Spalar P. R. $t$ and S. R. Allmaras. A one-equation turbulence model for aerodynamic flows. La Techerche Aerospatiale, 1:5-21, 1994.

[12] Fox Robert W., Pritchard Philip J., McDonald, Alan T. and Robert W. Fox. Fox and McDonald's introduction to fluid mechanics. John Wiley Sons, Inc., 2011.

[13] Friend Paul. Magnetic levitation train technology 1. progress report, Bradley university, 2004.

\section{Acknowledgement}

The Completion of any paper brings with it a sense of satisfaction, but it is never complete without thanking those people who made it possible as whose constant support has crowned our efforts with success.

We are extremely happy to acknowledge and expressed our sincere gratitude to our parents for their constant support and encouragement and last but not least friend and well-wishers for their help and cooperation and solution to the problem during the course of the paper.

KAUSHAL S. PATHARE 